\title{
A PERCEPÇÃO DO IDOSO INSTITUCIONALIZADO SOBRE OS BENEFÍCIOS DAS OFICINAS TERAPÊUTICAS
}

\author{
The institucionalized elderly perception about the benefits of \\ therapeutics workshops
}

Artigo Original

\section{RESUMO}

Objetivo: Compreender a percepção do idoso institucionalizado sobre os benefícios das oficinas terapêuticas. Métodos: Pesquisa exploratória, descritiva, com abordagem qualitativa, realizada em uma instituição de Belo Horizonte, Brasil. Participaram nove idosos residentes. Utilizou-se um roteiro semiestruturado de entrevista, com questões relativas à sua percepção sobre as oficinias terapêuticas. A Análise de Conteúdo seguiu o referencial de Bardin. Resultados: Foram agrupados em quatro categorias empíricas: A percepção das atividades realizadas nas oficinas terapêuticas; Compreendendo as oficinas terapêuticas como uma estratégia para a qualidade de vida; O desejo pelas atividades mesmo diante das limitações; As atividades terapêuticas resgatando o "ser" produtivo. Conclusão: Os idosos perceberam associação entre a prática das atividades terapêuticas e melhoria da qualidade de vida. Identificaram as oficinas como uma estratégia para a prevenção das perdas funcionais e/ou redução dos danos advindos da institucionalização.

Descritores: Enfermagem; Idoso; Instituição de Longa Permanência para Idosos; Condutas Terapêuticas; Pesquisa Qualitativa.

\section{ABSTRACT}

Objective: to understand the influence of therapeutic workshops in improving the functional capacity under the gaze of the elderly living in an institution of long-stay. Methods: Descritive, exploratory study, with qualitative aproach conducted in Belo Horizonte, Brazil. Nine individuals participated and was used a script to semistructured interview, with questions about therapeutic workshops. Content analysis followed the Bardin referential. Results: The results were grouped into four empirical categories: The perception of activities in the therapeutic workshops; Understanding therapeutic workshops as a strategy for quality of life; The desire for activities in the face of the limitations; Therapeutic activities rescuing the "be" productive. Conclusion: The elderly associate the practice of therapeutic activities to improve the quality of life and identify the workshops as a strategy for the prevention of functional loss and / or reduction of damages arising out of institutionalization.

Descriptors: Nursing; Elderly; Long-stay Institution for Elderly; Therapeutic Pipelines; Qualitative Research.

\author{
Mariluce Rodrigues da Silva ${ }^{(1)}$ \\ Natália Prates Vieira Santos ${ }^{(1)}$ \\ Rafaela Almeida Santos ${ }^{(1)}$ \\ Genilton Rodrigues Cunha ${ }^{(1)}$ \\ Lilian Machado Torres ${ }^{(1)}$
}

1) Faculdade Ciências Médicas de Minas Gerais - FCMMG - Belo Horizonte (MG)

- Brasil
Este artigo seguiu as normas e formatação estabelecidas pelo $5^{\circ} \mathrm{CIAIQ}$ - Congresso Ibero-Americano em Investigação Qualitativa. 


\section{INTRODUÇÃO}

Há algumas décadas atrás a população mais jovem predominava em relação ao contingente de 60 anos ou mais de idade dos dias atuais ${ }^{(1)}$. A relação entre longevidade e queda de fecundidade resulta no envelhecimento populacional em dimensões mundiais ${ }^{(2,3)}$. Aponta-se uma projeção de 2 bilhões de pessoas com mais de 60 anos, em $2050^{(4)}$.

O Brasil, seguindo a tendência mundial, sofre mudanças no seu perfil demográfico durante os últimos anos. A cada ano 700 mil pessoas se incorporam ao grupo de $\operatorname{idosos}^{(5)}$. Em 2010 somavam 20,5 milhões. Projeta-se para 2020, 30,9 milhões, chegando a32 milhões em 2025, elevando o Brasil para o sexto lugar entre os países com o maior número de idosos ${ }^{(6)}$. A mortalidade na população antes associadas a causas mais comuns da população mais jovem passa àquelas relacionadas a doenças crônicas, mais onerosas e debilitantes $^{(5)}$.

A mudança demográfica propiciou o início de discussões sobre a integração, a autonomia, a garantia dos direitos e a participação efetiva dos idosos na sociedade. Em outubro de 2003, o Ministério da Saúde brasileiro divulgou o Estatuto do Idoso ao garantir as oportunidades e facilidades, preservação da saúde física e mental, aperfeiçoamento moral, intelectual, espiritual e social ${ }^{(7)}$.

Além disso, questões relacionadas ao envelhecer passaram a constituir objetos de pesquisas e projetos de formação de profissionais, na busca da qualificação do cuidado prestado ${ }^{(5)}$.

Para muitos são necessários cuidados especiais e, quando isso não é possível no seio familiar, revestido de paciência e atenção, surgem as instituições de longa permanência para idosos, que dispõem de profissionais para auxiliá-los nas atividades do cotidiano ${ }^{(4,8,9)}$.

Mesmo desejando envelhecer com saúde, em estudo sobre o que pensam as pessoas de meia idade ${ }^{(10)}$, as alterações biopsicossociais do envelhecimento tornam o indivíduo mais vulnerável e alteram a dinâmica familiar, favorecendo a escolha dos responsáveis pela institucionalização dos $\operatorname{idosos}^{(11,12)}$.

De acordo com o Instituto Brasileiro de Geografia e Estatística (IBGE) ${ }^{(13)}$ aproximadamente 84 mil idosos brasileiros estavam distribuídos em 2.072 Instituições de Longa Permanência para Idosos (ILPI), em 2009. Uma resolução governamental regulamenta as atividades de tais instituições com destaque para promoção de atividades de lazer (físicas, recreativas e culturais) que estimulem a autonomia dos indivíduos e interação com a família e comunidade $^{(14)}$.
No entanto, percebe-se que a escassez de recursos não possibilita o desenvolvimento de atividades que concorram para a promoção da autonomia. Eficiência e eficácia das práticas ficam comprometidas pela carência de equipamentos e material de consumo, além da qualificação inadequada de profissionais ou voluntários, o que limita a progressão destas atividades ${ }^{(15)}$. Entretanto, estudo que avaliou o reflexo de ações extensionistas em instituições asilares concluiu que práticas lúdicas e educativas contribuem para a melhora na autoestima e saúde em geral dos idosos ${ }^{(3)}$.

Como não há regularidade e planejamento das atividades realizadas a institucionalização compromete a qualidade de vida do idoso, fato que pode ser constatado pelos prejuízos funcionais e $\operatorname{cognitivos}^{(9)}$. Ressalta-se isolamento dos familiares e de ligações sociais, apesar de satisfeitas outras necessidades como alimentação e condições higiênicas ${ }^{(16)}$.

As oficinas terapêuticas fazem emergir sentimentos de inserção em um grupo social e contribuem para os processos adaptativos mediante novas situações experimentadas. Quando os exercícios e tarefas são variados facilitam o reconhecimento de bem estar físico no contexto de interação ${ }^{(17,18)}$.

Em face desse contexto, questiona-se: quais seriam os benefícios das oficinas terapêuticas na melhoria da capacidade funcional na percepção dos idosos em uma ILPI? Assim esta pesquisa objetivou compreender a percepção do idoso institucionalizado sobre os benefícios das oficinas terapêuticas.

\section{MÉTODOS}

Trata-se de pesquisa exploratória com abordagem qualitativa realizada em uma ILPI, de Belo Horizonte, Brasil, com a participação de nove indivíduos residentes.

Puderam participar aqueles internos que atenderam aos critérios de inclusão pré-estabelecidos: condição cognitiva, referenciada pelo score do mini-mental (score $\geq 20$ para analfabetos e 25 para os que possuíam alguma escolaridade) e confirmada nos prontuários. Foram excluídos aqueles idosos que alcançaram no mini-mental o score < que 20 pontos.

Primeiramente e após a aprovação da pesquisa pelo Comitê de Ética em pesquisa os pesquisadores se aproximaram da ILPI e de seus representantes. Em seguida os idosos residentes foram reunidos para as explicações necessárias sobre a pesquisa, autorização para as gravações e assinaturas no Termo de Consentimento Livre e Esclarecido (TCLE).

A coleta de dados aconteceu por meio de entrevistas gravadas, realizadas em um espaço na própria instituição, 
momento em que estavam presentes apenas o idoso e o pesquisador. Utilizou-se um roteiro semiestruturado elaborado pelos pesquisadores contendo questões relacionadas às oficinas terapêuticas e sua percepção durante a sua realização. Os depoimentos não ultrapassaram 30 minutos cada um deles e puderam ser interrompidos quando o participante desejava. No entanto, em todos os encontros o roteiro foi seguido até seu término.

Os depoentes foram identificados pela letra "I", de idoso, seguida de um número inteiro para identificá-los. Para delimitação do número de participantes foi utilizado o critério de saturação de dados, quando as informações se tornaram repetidas e percebeu-se que os objetivos haviam sido atendidos ${ }^{(19)}$.

Encerrada a etapa das entrevistas, todos os depoimentos foram transcritos na íntegra. Em seguida ocorreu a leitura cuidadosa por todos os pesquisadores por diversas vezes no sentido de encontrar aqueles conteúdos com maior significado sobre o objeto em estudo.

A Análise de Conteúdo fundamentou-se no referencial de Bardin $^{(20)}$, que preconiza um conjunto de técnicas e procedimentos sistemáticos e objetivos para identificação do conteúdo das mensagens.

O estudo seguiu as orientações expressas na Resolução $466 / 2012^{(21)}$ que trata da pesquisa com seres humanos, e foi aprovado pelo Comitê de Ética em Pesquisa da Faculdade Ciências Médicas de Minas Gerais, sob o n ${ }^{\circ}$ 974.457/2015.

\section{RESULTADOS}

Participaram do estudo nove idosos residentes em uma ILPI do município de Belo Horizonte, estado de Minas Gerais, Brasil. Destes, cinco eram homens e quatro mulheres, com idade média de 70 anos. A média de residência nesse local foi de aproximadamente oito anos.

A partir da leitura dos depoimentos foram identificados e recortados aqueles que faziam emergir os significados mais expressivos sobre o tema. Em seguida, procedeuse à organização dos recortes com seu agrupamento por semelhança de sentidos. Ao final, foram condensados em quatro categorias: A percepção das atividades realizadas nas oficinas terapêuticas, Compreendendo as oficinas terapêuticas como uma estratégia para a qualidade de vida, $\mathrm{O}$ desejo pelas atividades mesmo diante das limitações, e As atividades terapêuticas resgatando o "ser" produtivo.

\section{A percepção das atividades realizadas nas oficinas terapêuticas}

Os participantes citaram que a dança e a música são as atividades preferidas por eles. Além disso, expressaram que tais atividades são fundamentais para promoção à saúde, já que podem, a princípio, ser percebidas como atividades físicas que visam a melhoria da qualidade de vida:
"Danço e canto. A dança movimenta todo o meu corpo, cabeça, tronco e membros. Melhora tudo: raciocínio, corpo, membros. Eu sou outra pessoa depois da dança, me sinto renovado." (I 2)
"O corpo fica bom, fica melhor. A dança é uma ginástica. O corpo fisicamente fica desembaraçado e quem está tocando, está se divertindo. Dançar é alegria: quem está dançando, está alegre. Eu sinto que quando acaba a dança, acabou a festa, acabou o baile." (I 8)
"Ah! Coisa boa é ouvir música, olhar a televisão, conversar. Aqui é muito bom!” (I 1)

Já os trabalhos manuais realizados na instituição como artesanato e bordado não foram referenciados como terapêuticos, mas como uma distração, pois os idosos não reconheciam que a ILPI ofertava outras atividades substitutas, embora alguns deles demonstravam o reconhecimento do benefício cognitivo:

"Não influi em nada. Eu já estou acostumada a fazer isso, então fica a mesma coisa. A minha cabeça bordando e sem bordar é a mesma coisa." (I 6)

"Às vezes eu faço essas coisas de papel, artesanato. A única coisa que sobra para fazer é isso. Ajuda a lembrar das coisas, a criar o pensamento." (I 5)

Observa-se que os depoimentos expressam certo conformismo em realizar atividades repetitivas e que alguns idosos não conseguem vislumbrar a realização de outras tarefas, mantendo-se nos mesmos afazeres diários.

Divergindo dos outros depoimentos, um dos idosos reconhece no bordado os benefícios que transcendem a funcionalidade:

\section{"As atividades são boas: eu mexo com tudo. Gosto de fazer artesanato. É bom! Eu fico bem. O coração às vezes pede para gente fugir dos problemas. Assim, a gente se distrai, eu fico feliz." (I 1)}

Verifica-se, portanto, que a maioria dos idosos demonstrou compreender a importância das diversas atividades oferecidas na ILPI para melhorias em seu cotidiano.

\section{Compreendendo as oficinas terapêuticas como uma estratégia para a qualidade de vida}

Observa-se que os idosos não souberam definir o que seriam as oficinas terapêuticas. Muitos deles associaram as atividades realizadas nas oficinas terapêuticas como atividades físicas. No entanto, foi possível perceber pelos depoimentos que eles reconheciam as oficinas terapêuticas 
traz alguns benefícios físicos e sociais, sempre com o foco na autonomia:
“Agora eu já posso me vestir. Eu me visto sozinho. Comer também. Que é o principal.” (I 5)
"O AVC (referindo-se ao acidente vascular cerebral) me prejudicou a perna, que melhora com o exercício. Comecei a me exercitar e melhorei $90 \%$, faltando pouquíssimo para $100 \%$, porque eu estava travado mesmo. Hoje eu consigo dançar um pouco, a perna já está movimentando melhor.” (I 2)
"Ajuda em tudo. Tudo fica melhor. Perna, braço, cabeça... Facilita movimentar. Traz muita coisa boa: alegria, conversar com os outros...” (I 3)
“As 'cadeiras' (referindo-se aos quadris) melhoram. $O$ movimento do corpo todo: é bom para o movimento $e$ para o equilibrio, ver pessoas diferentes." (I 8)

Uma das idosas atesta que está fazendo exatamente o que deseja, pois vislumbra que as oficinas terapêuticas permitem momentos de socialização, o que representa para ela grande prazer:

"Eu faço assim, um dia após o outro. Ajuda na amizade, sociedade... Tudo isso a gente tem que considerar. Sintome ótima, maravilhosa. Porque eu estou fazendo o meu desejo." (I 1)

Outro depoente compara os benefícios que as oficinas terapêuticas proporcionam aos efeitos esperados pelo uso de medicamentos, com se fosse um tratamento para uma patologia:

"Essas atividades são tão importantes que, muitas vezes, o melhor remédio é você ouvir uma boa música, ver um bom filme e ter uma boa conversa. Se a pessoa levar bem a sério, dá um alívio tremendo. Parece que eu tirei um peso das costas." (I 9)

Assim, entende-se ser necessário potencializar os benefícios das tarefas realizadas e ocupar o tempo ocioso a partir da discussão dos desejos dos idosos em relação às atividades terapêuticas. Nesse sentido é preciso fortalecer o desejo pela sua realização, mesmo frente às dificuldades individuais.

\section{O desejo pelas atividades mesmo diante das limitações}

Quando questionados como se sentiriam se houvesse a suspensão das atividades realizadas nas oficinas terapêuticas, alguns participantes do estudo apresentaram algumas formas de enfrentamento, como ouvir uma música a fim de preencher um vazio e buscar uma outra forma de prazer. Por outro lado, os mesmos idosos demonstraram certo conformismo caso cessem as atividades, expressando apenas um sentimento de lamentação, mas, mesmo assim, relatam que a sua existência é algo desejável:

"É claro, se puder fazer, eu faço com prazer, mas se não puder fazer... Eu tenho sempre a música, meu rádio, companheiro inseparável. Eu ouço música o tempo todo. ' (I 2)

“Lamento. Só lamento! Não vou gostar, mas tudo eu aceito com naturalidade. Claro que se eu puder fazer, eu vou fazer com prazer. Se não puder, fazer o quê? Quando tem que ficar aqui, eu fico." (I 4)

Nos depoimentos ficam claros que o idoso se abstém da possibilidade de participar na elaboração das atividades para ele, delegando tal competência somente aos profissionais de saúde da ILPI, uma limitação.

Sentimentos de tristeza foram relatados pelos entrevistados quando suscitou-se a possibilidade de não participarem das oficinas por questões pessoais relacionadas à incapacidade ou dores:

"Quando eu não posso fazer atividade, eu fico triste, chateada, mas não perco a razão. Ai eu fico constrangida. Não demonstro para as pessoas. Fico calada como sempre. Mais triste.” (I 1)

"Eu gosto da dança. Quando estão dançando aqui eu tento. As vezes fico aborrecido porque a gente quer dançar, mas você não dá conta: está com o corpo doendo, cansado, você não aguenta. Sinto falta da dança e prejudica o corpo porque fico parado, ai eu toco (algum instrumento) ou ajudo a tocar. A gente se sente atrofiado. É ruim! A gente fica abatida." (I 8)

Destaca-se que mesmo diante das limitações citadas, o fato de se praticar atividades terapêuticas passa a estar associado ao sentimento de ser visto como uma pessoa capaz e útil.

\section{Atividades terapêuticas resgatando o "ser" produtivo}

O passado de vida foi relembrado por um dos idosos, principalmente nas ocasiões em que exercia função laboral e tais lembranças associam-se à motivação para continuar sendo ativo:

"Eu trabalhei a vida toda; ficar à toa é muito duro! Eu acho que influi muito no cérebro você ficar em um lugar sem fazer nada. Depois que eu parei de trabalhar, eu fiz assim como uma distração pra não ficar à toa (refere-se ao bordado). Ficar em um lugar sem fazer nada é ruim demais, não é? Trabalhei 45 anos. Enquanto eu podia trabalhar, queria fazer o melhor; meu serviço ocupava o dia inteiro. Ficar à toa não dá, não é? ” (I 6) 
O ócio é evitado na visão daqueles que associam a realização de atividades na ILPI àquelas exercidas no passado laboral, e para eles, isso é importante:

"Mas quando você não está se sentindo bem, o que acontece é que tudo se torna mais dificil. [pausa]. É uma coisa que traz satisfação enorme: você se sentir útil. A pessoa muitas vezes para se sentir útil, tem que fazer alguma coisa. E essa coisa tem que ser boa, senão, ao invés de te alegrar, vai te entristecer.” (I 9)

"Atividade ocupa. É uma delícia. Eu trabalhei em casa também. Faço tudo: lavo, arrumo casa, passo roupa, pergunto para elas (cuidadoras) o que é que tem para ajudar. Tudo é bom." (I 1)

Os resultados demonstraram que os idosos percebem na sua vida os benefícios das atividades ofertadas nas oficinas terapêuticas e a importância de sua participação nas mesmas. Relacionam a sua participação e realização das atividades como um labor que resgata as habilidades adquiridas ao longo da vida, e evidenciam o desejo de sua continuidade.

\section{DISCUSSÃO}

$\mathrm{Na}$ atual situação do país, há um aumento progressivo do número de pessoas idosas e, consequentemente, maior demanda por instituições de longa permanência, as quais se configuram como um espaço residencial com serviços socioassistenciais e de saúde para uma assistência integral ${ }^{(14)}$.

Os residentes da ILPI apontam preferência por dança e música. Em um estudo sobre a influência que os bailes exercem em idosos institucionalizados ${ }^{(22)}$, pesquisadores afirmam que a dança minimiza as repercussões fisiológicas do envelhecimento, a partir do condicionamento físico, promovem independência funcional, interação social, e, consequentemente, melhoram a qualidade de vida. Outros autores $^{(23)}$ apontam ainda que os sons resgatam e fortalecem características pessoais e sociais, e contribuem para o envelhecimento saudável.

De acordo com a literatura, o ideal seria proporcionar uma musicoterapia que inclui o encontro entre o profissional musicoterapeuta e as pessoas que se dispõem à experiência e a prática musical, no caso os idosos, como uma ação que visa a potencialização de efeitos nos participantes. A experiência sensível pode (re)criar modos de relação, de pensamento, de ação, ou seja, de viver. Quando se cria musicalmente, aspectos cognitivos, culturais, corporais e afetivos são experienciados e tais ações desdobram-se para o campo do cotidiano, ecoando para os outros aspectos da vida dos participantes ${ }^{(24)}$.

Por meio dos achados, nota-se que as atividades manuais representam entretenimento e auxílio no resgate da funcionalidade. Seriam uma forma de liberdade de expressão e criatividade, auxiliando na prevenção da depressão e de outras doenças emocionais ${ }^{(25)}$. Outros teóricos ressaltam que essas tarefas revelam a linguagem peculiar do idoso no contexto terapêutico, ao oportunizar a expressão de suas potencialidades, organização e (re)organização de relacionamento consigo mesmo, com o outro e o mundo ${ }^{(26)}$.

De uma forma geral, as atividades realizadas em ambiente terapêutico resultam em benefícios de função motora e coordenação, além do cognitivo, bem-estar e autoimagem, que incrementam o processo criativo. Isso capacita os indivíduos para a reconciliação de conflitos emocionais e facilita o desenvolvimento pessoal por meio da autopercepção. Neste contexto, o conceito de arte deve ser ampliado para a inclusão da musicoterapia e dança, e não somente a realização de trabalhos manuais.

Os resultados incluem a superação das limitações antes experimentadas, desfrutando de alegria e bem estar, que os motiva a persistirem e continuar na prática das oficinas. O envelhecimento não é período desejado por muitas pessoas. Estudo realizado com idosos refere que muitos deles não desejam pensar no seu envelhecimento. Evitar tal experiência e a reflexão dela decorrente pode ser transformada em sofrimento e faz com que as pessoas não se preparem para as limitações que advêm desse processo ${ }^{(10)}$.

O envelhecimento saudável é considerado relevante na qualidade de vida do idoso nas publicações da Organização Mundial da Saúde ${ }^{(27)}$. Tal condição relaciona-se ao respeito às suas percepções e preferências, no que se refere à própria vida e suas dimensões objetivas (funcionalidade, saúde física, independência na vida diária, integração social e suporte familiar) e subjetivas (saúde mental, sentimentos e emoções).

Existe uma linha tênue entre a independência funcional e a qualidade de vida dos idosos institucionalizados, pois as intervenções para melhoria da funcionalidade resultam em ganhos na qualidade de vida e, como consequência, um envelhecimento saudável ${ }^{(28)}$.

Pode-se inferir que as oficinas terapêuticas mantém funcionalidade cognitiva e motora, e promovem a socialização, autonomia e independência nas atividades de vida diária. Qualidade de vida transcende a funcionalidade e a esfera objetiva, além de perpassar pela subjetividade e plenitude do ser humano, ao preservar seus pensamentos e vontades.

Para tanto, as atividades terapêuticas podem ressignificar a vida dos idosos institucionalizados no sentido de reverter ou minimizar a relação entre autonomia e independência e seu declínio devido à institucionalização, como os aspectos físicos e sociais, apresentada pela maioria das literaturas disponíveis. 
As oficinas terapêuticas foram percebidas pelos idosos como ajuda na redução do consumo de fármacos. O método não farmacológico é definido como aquele que intervém, na medida do possível, substituindo o uso de fármacos ${ }^{(29)}$. É um caminho a ser explorado, por representar maior segurança e menor número de intervenções. Ao avaliar os fatores associados à polifarmácia em idosos institucionalizados alguns autores identificaram que a funcionalidade é inversamente proporcional a polifarmácia, isto é, quanto mais independente for o idoso, menor o índice de medicações contínuas consumidas ${ }^{(30)}$.

A prática das atividades terapêuticas também diminui o uso de serviços de saúde, influenciando a vida dos idosos no contexto biopsicossocial ${ }^{(31)}$. Assim, uma parte dos idosos passa a depender menos dos serviços de saúde pela conquista de melhor qualidade de vida a partir da realização das atividades terapêuticas. Detecta-se, a partir daí, a otimização dos custos com a pessoa idosa e do sistema de saúde, além de minimizar o seu sofrimento no enfrentamento de processos patológicos e serviços superlotados.

Para tanto, os métodos não farmacológicos deveriam ser empregados na geriatria, gerontologia e em outros segmentos da saúde. Diante desse fato, faz-se necessário conhecer e aprimorar esses métodos em caráter científico a fim de expandir o conhecimento e intervenções nas diversas áreas do saber.

A possibilidade de suspensão das oficinas na ILPI, em sua maioria pela falta de profissionais para coordená-las, é remetida com tristeza pelos idosos. Muitos deles referem prazer e se sentem capazes de participar, o que os levou a sinalizar a perda de referências sem essa possibilidade, demonstrando ainda certo conformismo em aceitar a não oferta dessas atividades. Os resultados também demonstraram que, as experiências adquiridas ao longo da vida do ser humano produzem, em sua consciência, o limite de sua capacidade e a possibilidade de superação dos obstáculos e dificuldades.

Ao se deparar com a condição de institucionalização, percebe-se que o idoso passa a ser suprimido pela rotina, em geral fria e pesada de convivências e horários, que nega sua plenitude enquanto pessoa e se estagna com a rotina de sua nova moradia. Alguns estudiosos ${ }^{(32)}$ ressaltam que a forma de gestão da maioria das ILPI não permite aos residentes o sentimento de pertença em relação ao espaço, o que os leva a perda de sua individualidade e, muitas vezes, ao isolamento social.

Nesse sentido, percebe-se a importância dos profissionais de saúde em escutar as demandas do idoso e envolvê-lo no processo de discussão das atividades que devem a ele ser ofertadas, no intuito de poderem adquirir maior autonomia. Corroborando, alguns teóricos atestam a necessidade da importância de permitir que as pessoas idosas mantenham sua autonomia, a fim de se sentirem alegres e úteis quando realizam atividades independentes ${ }^{(16)}$.

A baixa adesão às oficinas terapêuticas é decorrente da falta de variação das atividades e sua inadequação às possibilidades físicas e intelectuais de cada indivíduo, que proporciona aumento do tempo ocioso e afastamento social que, por sua vez, promovem a sensação de abandono, impotência e de incapacidade diante da vida. Por outro lado, estudos $^{(22,33)}$ demonstraram que certas tarefas desenvolvidas pela instituição são, muitas vezes, percebidas pelos residentes como obrigatórias e/ou desvinculadas de seus verdadeiros interesses. Sendo uma das soluções para este problema, um maior estímulo a motivação interna para a prática de lazer na ILPI, acessando as experiências de lazer dos residentes para que as propostas institucionais sejam mais condizentes com os interesses e vontades destes.

Constatou-se que quando existem atividades programadas e, por algum motivo físico, os idosos não podem participar, isso é percebido com tristeza, ao representar para eles uma perda, e a capacidade de enfrentamento, às vezes, não é suficiente. Fica evidente a necessidade de alternativas que promovam a inclusão dos idosos nas diversas situações que se apresentam. Estudo que analisou os diversos sentimentos experimentados pelos idosos na realização de tarefas observou-se que estar ocupado com atividades gratificantes e significativas diminui sentimentos de solidão, tristeza, incapacidade, além de melhorar o humor, proporcionar a motivação, aumentar os níveis de autoestima e incentivar os hábitos saudáveis de vida ${ }^{(34)}$.

As tarefas desempenhadas nas oficinas terapêuticas ou, até mesmo as cotidianas, remetem os participantes à época em que desempenhavam atividades laborais, permitindo o preenchimento do tempo e motivação para estar sempre em movimento. Ao analisar as repercussões da aposentadoria na qualidade de vida em idosos o trabalho foi definido como fonte de prazer e satisfação, e não apenas financeira. Permite sentimento de utilidade e maior capacidade de enfrentamento após a aposentadoria, o que facilita a reestruturação de sua própria identidade, sem afetar o seu papel social ${ }^{(35)}$.

Apesar de perdas e limitações o envelhecimento saudável é um desejo unânime de todo ser humano ${ }^{(31)}$. Observa-se no presente estudo que, mesmo conhecendo suas limitações, alguns idosos buscam uma forma de ocupação que satisfaça e traga prazer, como um mecanismo para sua adaptação num contexto de vulnerabilidade e fragilidade decorrentes da institucionalização. Uma das formas de se viver plenamente essa fase da vida seria experimentar atividades que proporcionem satisfação pessoal e contribuam para manutenção da identidade, personalidade do indivíduo e a maneira de ver e pensar o mundo. 
As limitações do estudo referem-se ao fato de ter sido realizado em uma ILPI, o que pode não permitir a sua generalização. No entanto, tais resultados podem ser discutidos em realidades semelhantes.

\section{CONSIDERAÇÕES FINAIS}

A dependência dos idosos é um fenômeno complexo, principalmente quando envolve a institucionalização, que demanda vários tipos de intervenção, como as atividades ofertadas nas oficinas terapêuticas que procuram minimizar ou cobrir a ausência de autonomia no cotidiano do idoso.

Os resultados apontam que as oficinas realizadas na instituição concorrem para melhora na qualidade de vida são percebidas pelos idosos como um caminho para a maior independência e autonomia. Há prazer na participação daquelas atividades que são acompanhadas de musicalidade e movimentos corporais. O estar ocupado viabiliza a interligação no sentido laboral, relembrado de épocas passadas, e isso faz emergir o sentimento de se sentir útil no meio em que vivem.

Como repercussão na prática diária dos profissionais de saúde envolvidos com ILPI, deve-se ressaltar que a escolha das atividades, o processo para sua realização e a avaliação precisa considerar os desejos, maior facilidade e as demandas dos idosos envolvidos. A associação entre manterse ocupado e necessitar de menor carga de medicamentos indica um caminho para os males do envelhecimento, ou seja, um método não farmacológico eficaz.

Os métodos não farmacológicos inseridos no contexto do idoso institucionalizado são alternativas que podem ser trabalhadas e implantadas por meio das oficinas terapêuticas nas ILPI. A desmedicalização é considerada um desafio a ser alcançado, porém depende mais da vontade e postura dos profissionais de saúde no cuidado prestado à terceira idade. Nesse contexto, o cuidado passará a ser centrado nas demandas do idoso, minimizando o seu sofrimento e permitindo a conquista diária para manter as suas capacidades cognitivas e funcionais, possibilitando um cuidado humanizado e integral.

Assim, as políticas públicas deveriam considerar a necessidade de educação permanente dos profissionais de IPLI, no sentido de sua capacitação para a escolha das atividades mais adequadas em relação aos recursos disponíveis e análise das limitações dos indivíduos envolvido. Os idosos também devem ser contemplados, já que não se pode eximi-los da corresponsabilização pela sua saúde, a fim de torná-los mais proativos nas escolhas e adaptação das atividades às suas demandas.

Novos estudos que aprofundem no tema exposto são necessários, uma vez que a pirâmide etária sofre mudanças continuamente e a população idosa está em franco crescimento. O presente estudo foi apresentado e levado à discussão durante o $5^{\circ}$ Congresso Ibero-Americano em Investigação Qualitativa( ${ }^{(29)}$ (CIAIQ), o que referenda a necessidade de divulgação e realização de novos trabalhos.

\section{REFERÊNCIAS}

1. Vasconcelos AMN, Gomes MMF. Transição demográfica: a experiência brasileira. Epidemiol Serv Saúde 2012;21(4):539-48.

2. Miranda GMD, Mendes ACG, Silva ALA. O envelhecimento populacional brasileiro: desafios e consequências sociais atuais e futuras. Rev Bras Geriatr Gerontol. 2016;19(3):507-519.

3. Oliveira JHS, Lima DC, Fernandes LA, Pereira AA, Fernandes CA. Envelhecer com qualidade: reflexo de ações extensionistas em instituições asilares. Rev Ciênc Ext. 2016;12(2):141-152.

4. Soares IGE, Rech V. Prevalência de quedas em idosos institucionalizados no Brasil: uma revisão integrativa. Rev Kairós Geront. 2015;18(4):47-61.

5. Veras R. É possível, no Brasil, envelhecer com saúde e qualidade de vida? Rev Bras Geriatr Geront. 2016;19(3):81-382.

6. Malta DC, Oliveira MR, Moura EC, Silva SA, Zouain CS, Santos FP et al. Fatores de riscos e proteção para doenças crônicas não transmissíveis entre beneficiário de saúde suplementar: resultados do inquérito telefônico vigente. Ciênc Saúde Coletiva. 2011;16(3):2011-22.

7. Brasil. Lei no 10.741 , de 1 de outubro de 2003. Estatuto do idoso. Brasília, 2003.

8. Perlini NMOG, Leite MT, Furini AC. Em busca de uma instituição para a pessoa idosa morar: motivos apontados por familiares. Rev Esc Enferm USP. 2007:41(2):229-236.

9. Silva MV, Figueiredo MLF. Idosos institucionalizados: uma reflexão para o cuidado de longo prazo. Enfermagem em Foco. 2012:3(1):22-24.

10. Camara, S; Rigoto Mari, F; Guimarães Alves, G; Rangel Ganso de Castro Aerts, D. O processo de envelhecimento e a saúde: o que pensam as pessoas de meia-idade sobre o tema. Rev. Bras. Geriatr. Gerontol. 2016;19:35-44.

11. Lisboa CR, Chianca TCM. Perfil epidemiológico, clínico e de independência funcional de uma população idosa institucionalizada. Rev Bras Enferm. 2012;65(3):482-87. 
12. Alencar MA, Bruck NNS, Pereira BC, Câmara, TMM, Almeida, RDS. Perfil dos idosos residentes em uma instituição de longa permanência. Rev Bras Geriatr Gerontol. 2012;15(4):786-796.

13. Instituto Brasileiro de Geografia e Estatística (IBGE). Atlas do Censo demográfico do IBGE. 2010.

14. Brasil. Ministério da Saúde; Agência Nacional de Vigilância Sanitária. Resolução RDC no 283, de 26 de setembro de 2005. Aprova o Regulamento Técnico que define normas de funcionamento para as Instituições de Longa Permanência para Idosos [Internet]. Brasília; 2005 [citado 2015 dez. 18]. Disponível em: Disponível em: http://bvsms.saude.gov.br/bvs/saudelegis/ anvisa/2005/res0283_26_09_2005.html

15. Moura GA, Souza, LK. Lazer e idoso institucionalizado: tendências, problemas e perspectivas. Licere. 2012;16(2):1-21.

16. Lima APM, Gomes KVL, Frota NM, Pereira FGF. Qualidade de vida sob a óptica da pessoa idosa institucionalizada Rev Bras Promoç Saúde. 2016;29(1):14-19.

17. D’Orsi E, Xavier AJ, Ramos, LR. Trabalho, suporte social e lazer protegem idosos da perda funcional: Estudo epidoso. Rev. Saúde Pública. 2011;45(4):685692.

18. Cabral JR, Alencar DL, Vieira JCM, Cabral LR, Ramos VP, Vasconcelos EMR. Oficinas de educação em saúde com idosos: Uma estratégia de promoção de qualidade de vida. Rev Enf. 2015;1(2):71-75.

19. Fontanela BJB, Ricas J, Turato ER. Amostragem por saturação em pesquisas qualitativas em saúde: contribuições teóricas. Cad Saúde Pública. 2008;24(1):17-27.

20. Bardin, L. Análise de conteúdo. São Paulo, 2011.

21. Brasil. Resolução no 466, de 12 de dezembro de 2012. Regulamenta pesquisas com seres humanos. Ministério da Saúde, 2012.

22. Oliveira RG, Madruga VA, Verlengia R, Tolocka RE. Características pessoais e participação em bailes numa instituição de longa permanência para idosos. Rev Bras Cineantropometria \& Desempenho. 2010;12(4):295301.

23. Mozer NMS, Oliveira, SG, Portella, MR. Musicoterapia e exercícios terapêuticos na qualidade de vida de idosos institucionalizados. Estudos Interdisciplinares sobre o Envelhecimento. 2011;16(2):229-244.
24. Arndt AD, Cunha R, Volpi S. Aspectos da prática musicoterapêutica: contexto social e comunitário em perspectiva. Psicol Soc. 2016;28(2):387-95.

25. Santos JR, Pavão, YMP. Empreendedorismo social: Estudo em uma instituição de Longa Permanência para Idosos (ILPI). 2014 Disponível em: http://www. fafipa.br/site/files/2016a/anais_adm2015/COM10\%20 NOME.pdf

26. Guedes MHM, Mota HG, Almeida MEF. Efeito da prática de trabalhos manuais sobre a autoimagem de idosos. Rev Bras Geriatr Gerontol. 2011;14(4):731-42.

27. Organização Mundial da Saúde(OMS). WHOQOL and spirituality, religiousness and personal beliefs (SRPB). Report on WHO consultation. WHO, Genebra. 1998; $22 \mathrm{pp}$.

28. Murakami L, Scattolin F. Avaliação da independência funcional e da qualidade de vida de idosos institucionalizados. Rev. Méd. Herediana, 2010;21(1):18-26.

29. Osório SMB, Silva Júnior, LG, Nicolau, AIO. Avaliação da efetividade de métodos não farmacológicos no alívio da dor do parto. Piauí. Rev Rede Enferm. 2014;15(1):174-84.

30. Luccetti G, Granero AN, Pires SL, Gorzoni ML. Fatores associados à polifarmácia em idosos institucionalizados. Rev Bras Geriatr Gerontol. 2010;13(1):51-8.

31. Fleuri ACP, Almeida ACS, Diniz AJ, Magalhães LAD, Ferreira LH, Horta NC, et al. Atividades lúdicas com idosos institucionalizados. Enfermagem Revista. 2013;16(1):50-7.

32. Costa MCNS, Mercadante EF. O idoso residente em ILPI (Instituição de Longa Permanência) e o que isso representa para o sujeito idoso. Rev Kairós Gerontologia. 2013;16(2):209-22.

33. Moura GA, Souza LK. Práticas de lazer de idosos institucionalizados. Movimento. 2013;19(4):69-93.

34. Teixeira LMF. Solidão, depressão e qualidade de vida em idosos: um estudo avaliativo exploratório e implementação-piloto de um programa de intervenção. [Dissertação-Mestrado]. [acesso em 2016 Mar 5] Disponível em: http://repositorio.ul.pt/jspui/ bitstream/10451/2608/1/ulfp037460_tm_tese.pdf

35. Costa CO. Aposentadoria e Qualidade de Vida. [Dissertação- Mestrado]. Pontifícia Universidade Católica do Rio Grande do Sul. Instituto de Geriatria e Gerontologia. 2010; [acesso em 2016 Mar 5] Disponível em: http://tede2.pucrs.br/tede2/handle/tede/2619 


\section{Endereço primeiro autor:}

Mariluce Rodrigues da Silva

Faculdade Ciências Médicas de Minas Gerais

Alameda Ezequeiel Dias, 275

Bairro: Centro

CEP 30110-130 - Belo Horizonte - MG - Brasil

E-mail: mariluce-rodrigues@live.com.br

\section{Endereço para correspondência:}

Lilian Machado Torres

Faculdade Ciências Médicas de Minas Gerais

Alameda Ezequeiel Dias, 275

Bairro: Centro

CEP 30110-130 - Belo Horizonte - MG - Brasil

E-mail: lilian.torres@cienciasmedicasmg.edu.br 